\title{
Remote sensors of Vegetable Activity to protect areas resistant to low soil moisture
}

\author{
California potential water reserve in regions with high vegetable activity and extreme \\ drought conditions
}

Author: Fernando Roque. fernando@astst.info

California has suffered during 2020 and 2021 extremely drought conditions and low moisture during the rainy seasons of both years. Four facts are common for this situation:

1) The region of Corte de Madera has an excellent resilience to drought conditions even during the dry season. This matter comes from the readings of Vegetable Activity using the Fractions of Absorbed Photosynthetically Active Radiation (FAPAR) of the European Copernicus program using the Sentinel III satellite.

2) As a comparison, the Golden Gate reserve of California does not have the same resistance to droughts and it is near Corte de Madera, on the other side of the San Francisco Bay.

3) Napa Valley had a severe wildfire in August 2020. The FAPAR measurement for the rainy season of 2020 (January to April) shows a low vegetable activity.

4) Dixie region also had a drastic wildfire in July 2021. The FAPAR level was very low for the rainy season of the years 2020 and 2021 (November to April).

The FAPAR indicator has a value range between 0 and 0.94 . Figure 1 shows the comparison of FAPAR for Corte de Madera and Golden Gate in San Francisco Bay, California. Both regions are close to each other in the western part of the Bay. However, Corte de Madera has a vegetable activity between 0.68 and 0.81 despite the extreme drought conditions of the State during these two years. Golden Gate region has a low FAPAR value between 0.4 and 0.5. The October drought map of the US Drought monitor is in figure 1.

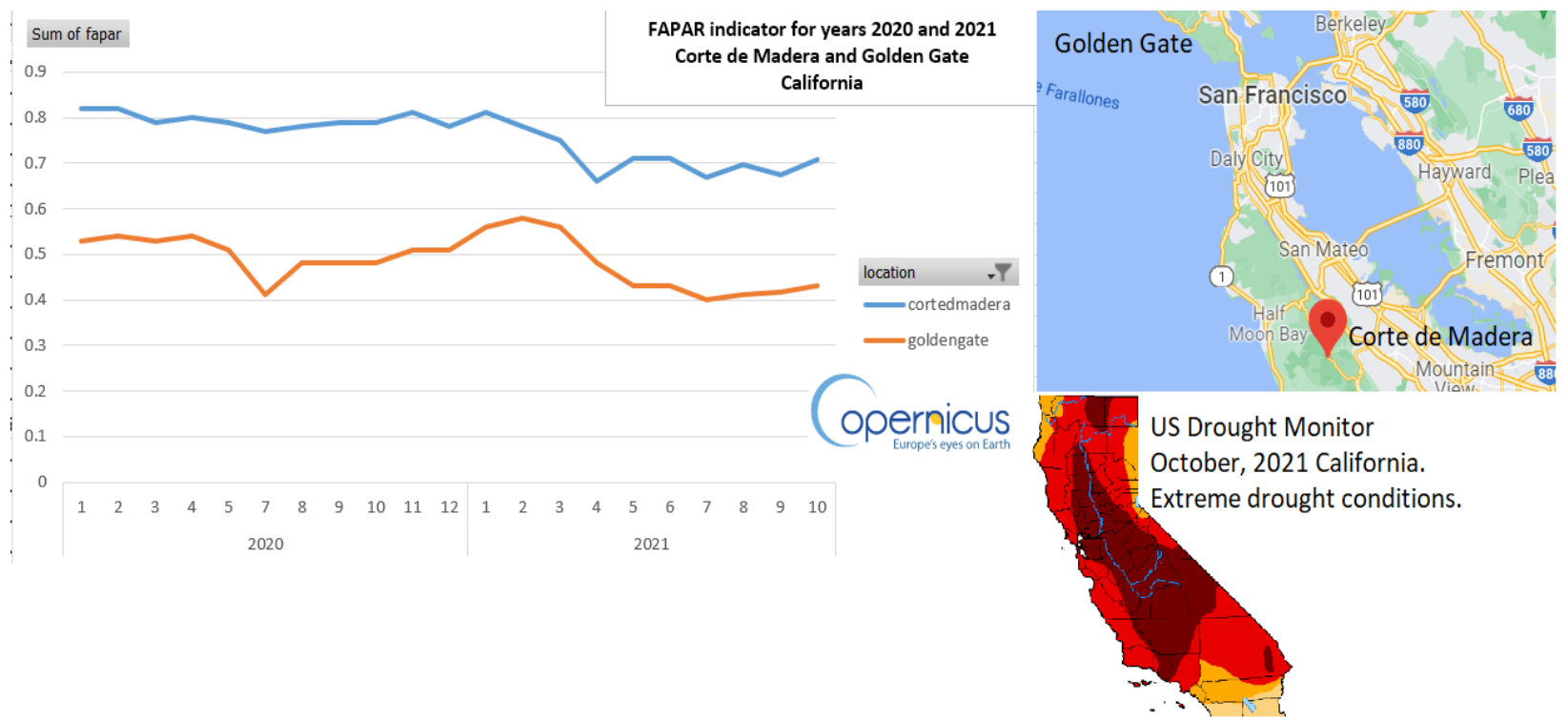

Figure 1 Corte de Madera and Golden Gate FAPAR for years 2020-2021 
The continuous surveillance of Corte de Madera using remote sensors can be useful to prevent a wildfire disaster. This region has the potential to be a water reservoir and moisture reserve with its high resistance to 22 months of severe drought in the San Francisco Bay.

FAPAR surveillance can be useful to detect possible risks of wildfires. Napa Valley and Dixie regions experimented a decrease in vegetable activity at the end of the rainy season in April. This could trigger an alarm in the region that the low moisture could lead to wildfires. Figure 2 shows the FAPAR indicator for Napa Valley and Dixie regions for the years 2020 and 2021.

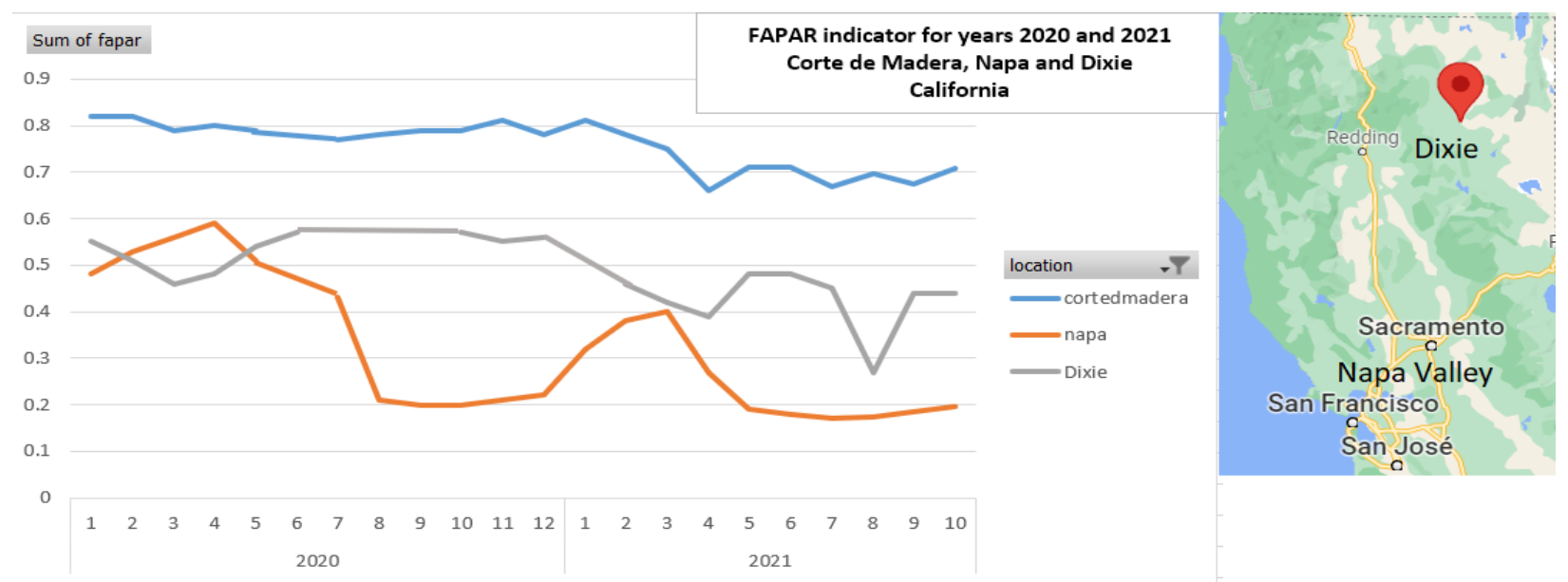

Figure 2 FAPAR indicator for Napa Valley and Dixie for wildfires conditions

Napa Valley and Dixie had low FAPAR indicator during the years 2020 and 2021 with a maximum of 0.6 even during the rainy season from November to April. Napa Valley suffered a severe decline in FAPAR vegetable indicators just after the rainy season of 2020 in April. It happened before the wildfires that affect the region in August 2020. After the wildfires look at the extremely low FAPAR indicator up to October 2021. This situation shows the high impact of wildfires in the recovery of a region after a disaster. Dixie region had a declining rainy season of 2020 and 2021 (November to April). The wildfires started in August and the FAPAR indicator fell below 0.3. The FAPAR recovery up to October 2021 is 0.45. But it is an extremely low FAPAR indicator compared with Corte de Madera. 